\title{
THREE-DIMENSIONAL EFFECTS OF RECTANGULAR EMBANKMENT LOADING PLACED ON SOFT GROUND
}

\author{
*Hajime Ito ${ }^{1}$, Atsushi Iizuka ${ }^{2}$ and Hideki Ohta ${ }^{3}$ \\ ${ }^{1}$ JIP Techno Science Corporation, Japan; \\ ${ }^{2}$ Kobe University, Japan; ${ }^{3}$ Chuo University, Japan
}

*Corresponding Author, Received: 03 March 2020, Revised: 29 March 2020, Accepted: 13 April 2020

\begin{abstract}
Although geotechnical problems are inherently three-dimensional (3D), they are frequently approximated by one-dimensional (1D) or two-dimensional (2D) analyses. These simplifications are often based on certain assumptions. However, the use of simplified analyses under conditions where the 3D effects cannot be ignored reduces the accuracy of future predictions. This study aimed to investigate the relevance of plane strain analyses and 3D analyses, considering the 3D effects on typical load problems. In this study, 3D parametric analyses were conducted using several models with different embankment lengths in the longitudinal direction. The elastoplastic constitutive model (The Sekiguchi-Ohta model) and the linear elastic model were used to investigate the influence of the embankment shape and soil material on the 3D effects. This study confirms that the 3D effect factors help estimate the displacement of each part while considering the 3D effects from the analysis results obtained by applying the plane strain condition.
\end{abstract}

\section{Keywords: Three-dimensional effects, Embankment, Settlement, Lateral displacement, FEM}

\section{INTRODUCTION}

Several 3D finite element method (FEM) programs have been developed since the 1990s $[1,2]$, and with the recent improvements in computer software and hardware technology, performing large and complex geotechnical 3D finite element analysis is no longer challenging and expensive. Moreover, many constitutive models have been developed in the last 50 years, contributing to the development of geotechnical analysis using FEM [3-12]. Each model can express ground behaviors, such as anisotropy, dilatancy characteristics, over- and secondary consolidation, and creep. However, engineers must set values of multiple input parameters by trial and error.

In this study, the focus is on the spatial deformation of the staged construction of an embankment on soft soil. To accurately predict the spatial deformation of the construction work of the embankment, it is important to obtain values of input parameters by back analysis from the field displacement of the test embankment. Applying the plane strain condition to the back analysis under conditions where the $3 \mathrm{D}$ effects cannot be ignored reduces the accuracy of future predictions. However, it is difficult to calibrate parameters in a huge number of 3D analyses.

In the actual construction sites of the embankment, extensive research comparing the results of 2D and 3D FEM has been conducted [1320]. Table 1 summarizes the results of these studies and shows that as the ratio of the length to the width $(\mathrm{L} / \mathrm{B})$ of the embankment decreases, the 3D effects become significant. However, these studies compare the 2D and 3D analyses under the local conditions of their respective sites. Furthermore, systematic knowledge to design another site is not easily available. Therefore, in this study, a parametric analysis was performed considering multiple embankment shapes and soil materials. These numerical experiments were performed using the Sekiguchi-Ohta model and PLAXIS3D program, assuming a conventional embankment work. This study aimed to propose a method that takes into account the 3D effects of the loading problem under the plane strain condition for analyses of a huge number of cases. This is an important and efficient future prediction technology for observing construction sites.

Table 1 Applicability of plane strain conditions in embankment construction

\begin{tabular}{ccccc}
\hline & L/B & Settlement & Lateral displacement & Material model \\
\hline Tschuchnigg (2018) & 4.0 & Applicable & Applicable & Elasto-viscoplastic \\
Bergado (2008) & 3.0 & Applicable & - & Elastoplastic \\
Chai (2015) & 2.0 & Applicable & Not applicable & Elastoplastic \\
Chaiyaput (2014) & 1.0 & Not applicable & - & Elastoplastic \\
\hline
\end{tabular}




\section{NUMERICAL EXPERIMENT MODELS}

Fig. 1 illustrates the embankment shape used in this study. This is a conventional cross-sectional shape used in actual construction projects in Japan. It was assumed that the clay layer was deposited on the firm-base layer with low compressibility. The width (B) and height (h) of the embankment were $60 \mathrm{~m}$ and $10 \mathrm{~m}$, respectively.

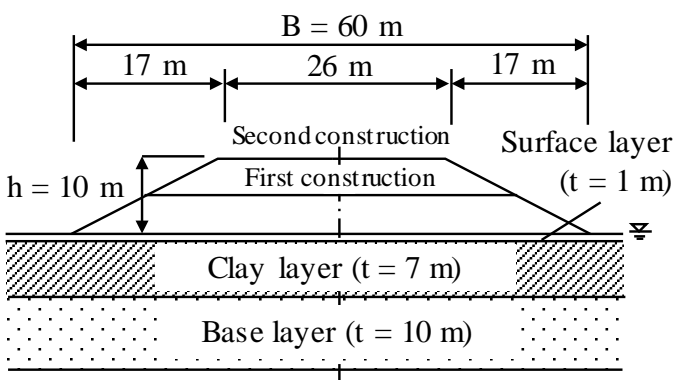

Fig.1 Profile of the loading problem

In general, the plane strain condition is used to solve such loading problems using FEM. It is assumed that the length (L) of the embankment is sufficiently larger than B and there is no change in the ground or load conditions in the longitudinal direction. However, in practice, the length of the embankment is restricted by the staged construction, and the displacement of the ground surface and underground frequently deviates from the plane strain condition. This also applies to test embankments. Therefore, the 3D effects of longterm deformation were confirmed through parametric analysis using several models with different embankment lengths.

Fig. 2 shows seven model cases of embankment shapes with different ratios $(\mathrm{L} / \mathrm{B}=5.0,4.0,3.0,2.0$, $1.5,1.2$, and 1.0). In the model fig. 2 [A], the embankment length is equal to the full width, and the displacement constraint condition is set on the end-face of the embankment. Therefore, the model fig. 2 [A] represents the plane strain condition, and this model was used as a reference to confirm the behaviors of models fig. 2 [B] - fig. 2 [G]. The finite element models were symmetric quarter models with symmetric boundary conditions, as shown in Fig. 3.

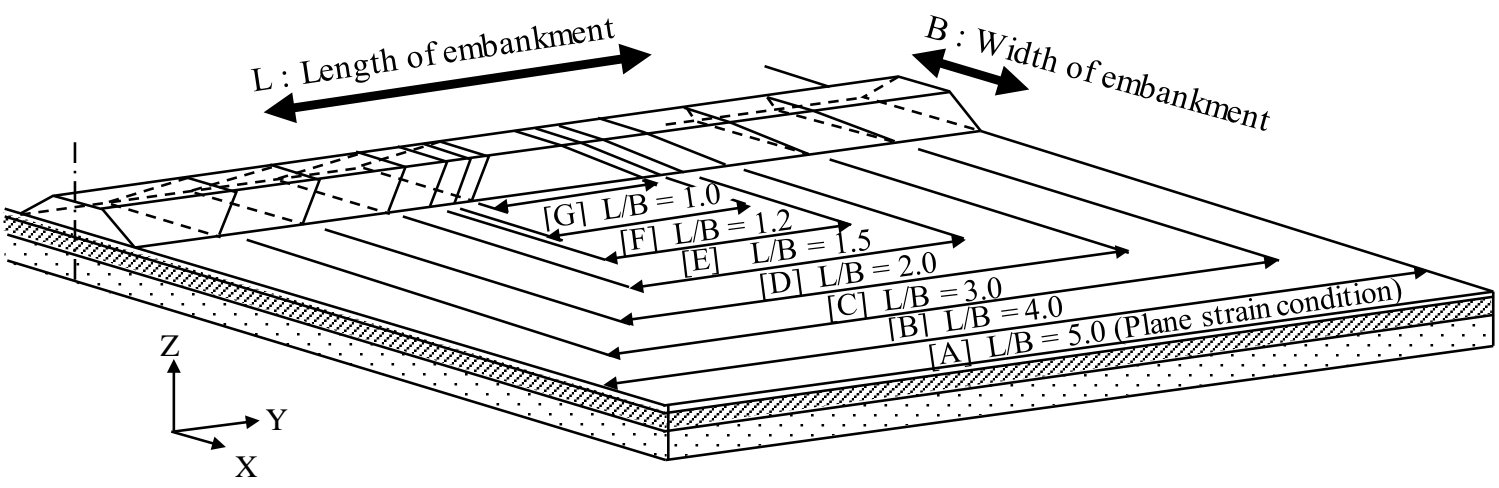

Fig. 2 Model cases of embankments with different L/B

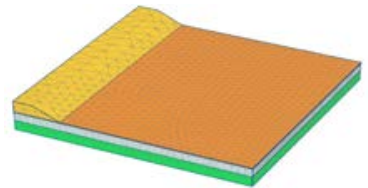

[A] $\mathrm{L} / \mathrm{B}=5.0$

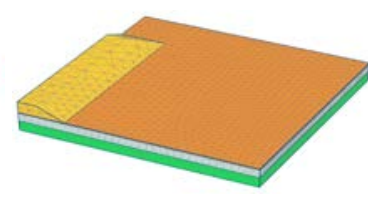

[B] $\mathrm{L} / \mathrm{B}=4.0$

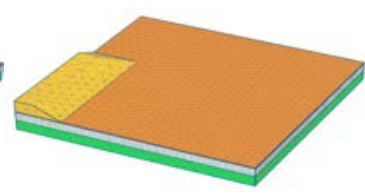

[C] $\mathrm{L} / \mathrm{B}=3.0$

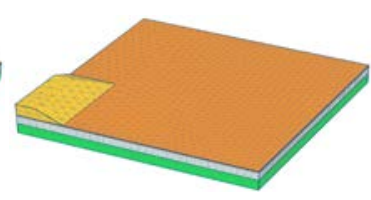

[D] $\mathrm{L} / \mathrm{B}=2.0$

(Plane strain condition)

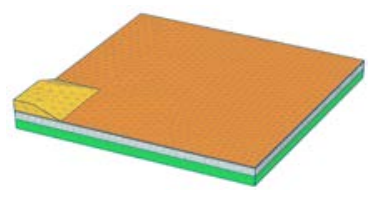

[E] $\mathrm{L} / \mathrm{B}=1.5$

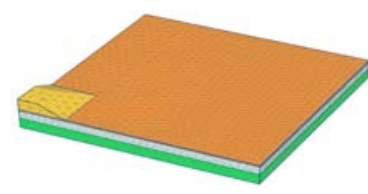

[F] $\mathrm{L} / \mathrm{B}=1.2$

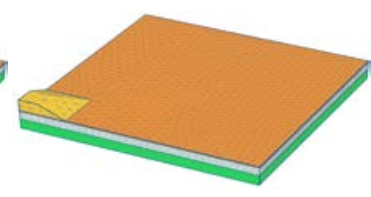

[G] $\mathrm{L} / \mathrm{B}=1.0$

Fig. 3 Finite element models of embankments with different L/B 
Table 2 Staged construction of embankment

\begin{tabular}{lcc}
\hline \multicolumn{1}{c}{ Step } & Hill height & Construction period \\
\hline Initial stress analysis (K0) & $0 \mathrm{~m}$ & - \\
First construction & $5 \mathrm{~m}$ & 40 days \\
Consolidation & $5 \mathrm{~m}$ & 25 days \\
Second construction & $10 \mathrm{~m}$ & 40 days \\
Consolidation & $10 \mathrm{~m}$ & Until dissipation of excess pore pressure \\
\hline
\end{tabular}

To confirm the 3D effects of each model, the results of the model fig. 3 [A] were considered for comparison, rather than the $2 \mathrm{D}$ analysis results obtained using the plane strain element. This is to prevent the difference in deformation performance between the solid elements and plane strain elements, and the corresponding effects due to the differences in the mesh shape.

Table 2 lists the analysis procedure and construction parameters of the embankment.

\section{MATERIAL MODEL OF SOIL}

The linear elastic model and the elastoplastic model were used to confirm the influence of the material model on the 3D effects. The SekiguchiOhta model, which considers the compression and shear behavior of soil, was used as the elastoplastic model. It is widely used in Japan because it considers the occurrence of plastic strain accompanying the anisotropy of naturally deposited clay. A procedure (as illustrated in Fig. 4) to determine the input parameters of the SekiguchiOhta model was previously developed by Iizuka et al. [21].

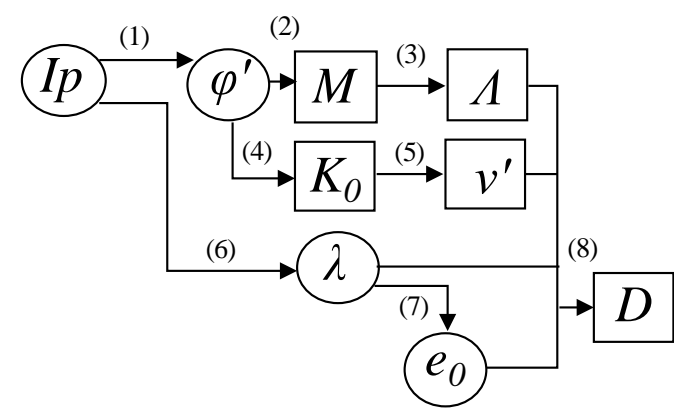
(1) $\sin \varphi^{\prime}=0.81-0.233 \log I p$
Kenney (1959)
(2) $M=6 \sin \varphi^{\prime} /\left(3-\sin \varphi^{\prime}\right)$
(3) $\Lambda=M / 1.75$
(4) $K_{0}=1-\sin \varphi^{\prime}$
(5) $v^{\prime}=K_{0} /\left(1+K_{0}\right)$
Karube (1975)
Jaky (1944)
(6) $\lambda=0.015+0.007 I p$
(7) $e_{0}=3.78 \lambda+0.156$
(8) $D=\lambda \Lambda /\left[M\left(1+e_{0}\right)\right]$
Ohta (1971)

Fig. 4 Procedure used to determine the input parameters of the Sekiguchi-Ohta model
Here, the parameters were calculated using the flowchart for normally consolidated clay. The plasticity index (PI) was assumed to $20 \%$. Table 3 lists the values of the input parameters.

For the linear elastic model, Young's modulus E was set assuming that the $\mathrm{N}$ value was approximately $3(\mathrm{E}=700 \mathrm{~N})$. Besides, the materials of the base layer, surface layer, and embankment were assumed to be linearly elastic with high permeability coefficients.

Table 3 Material parameters of the clay layer

\begin{tabular}{lcc}
\hline Parameter & $\begin{array}{c}\text { Elastoplastic } \\
\text { model }\end{array}$ & $\begin{array}{c}\text { Linear elastic } \\
\text { model }\end{array}$ \\
\hline$M$ & 1.220 & - \\
$\Lambda$ & 0.697 & - \\
$D$ & 0.051 & - \\
$v^{\prime}$ & 0.344 & 0.344 \\
$K_{0}$ & 0.524 & 0.524 \\
$e_{0}$ & 0.742 & - \\
$E\left(\mathrm{kN} / \mathrm{m}^{2}\right)$ & - & 2100 \\
$\gamma_{\text {unsat }}\left(\mathrm{kN} / \mathrm{m}^{3}\right)$ & 17.0 & 17.0 \\
$\gamma_{\text {sat }}\left(\mathrm{kN} / \mathrm{m}^{3}\right)$ & 18.0 & 18.0 \\
$k(\mathrm{~m} / \mathrm{day})$ & 0.003 & 0.003 \\
\hline
\end{tabular}

\section{3D EFFECT OF LOADING PROBLEM}

\subsection{D Effect Factor}

The displacements of the ground surface and underground were confirmed from the analysis results of the seven models with varying embankment lengths. Moreover, to express the relationship between the $\mathrm{L} / \mathrm{B}$ of the embankment and the change in displacements in each part quantitatively, the 3D effect factor is defined, as shown in Fig. 5.

This factor is indicated by the ratio of the displacement of each model with different L/B (fig. 3 [B] - fig. 3 [G]) to the displacement in the plane strain condition (fig. 3 [A]). Fig. 6 shows the relationship between $\mathrm{L} / \mathrm{B}$ and the $3 \mathrm{D}$ effect factor of displacement for each part. 


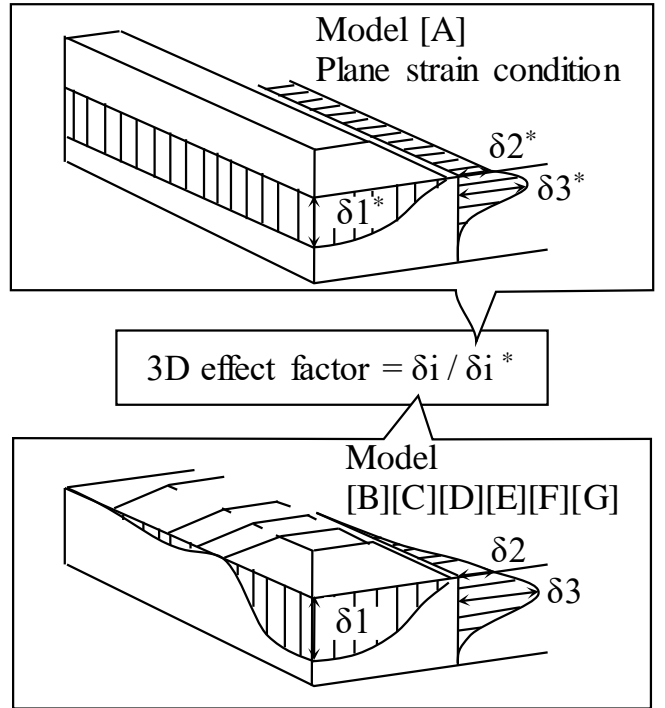

$\delta 1$ : Settlement

$\delta 2$ : Lateral displacement (Ground surface) $\delta 3$ : Lateral displacement (Underground)

Fig. 5 Method of calculating the 3D effect factor

(a) Settlement

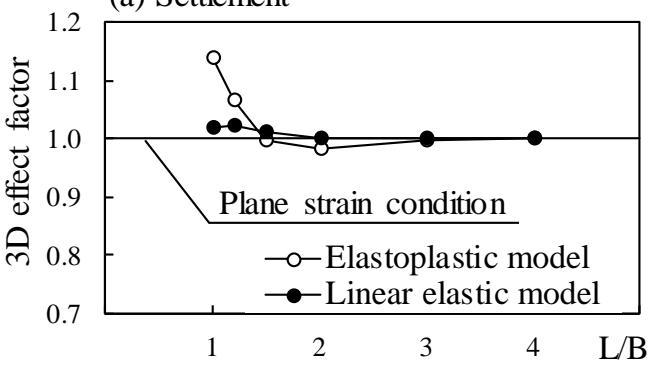

(b) Lateral displacement (Ground surface)

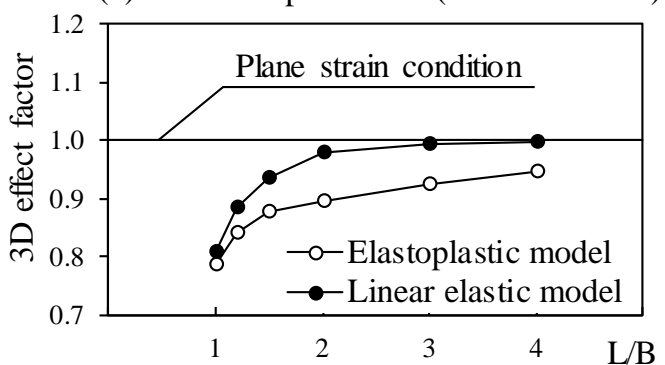

(c) Lateral displacement (Underground)

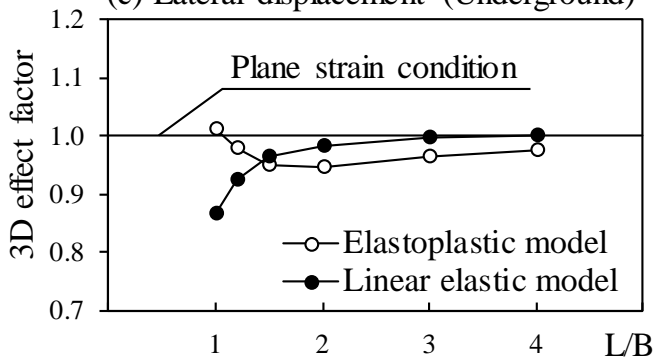

Fig. 6 3D effect factor of displacement
The 3D effect factors of the elastoplastic model and linear elastic model have different curved shapes. This result shows that the $3 \mathrm{D}$ effects of the loading problem on soft ground are influenced by the embankment shape and the soil material model.

Furthermore, the 3D effect factors of displacement at each part have different curved shapes. This confirms that to predict a displacement while considering the $3 \mathrm{D}$ effect from the displacement in the plane strain condition, it is necessary to consider a different $3 \mathrm{D}$ effect factor for each part. It is evident from the relationship of the $3 \mathrm{D}$ effect factor of each part that the settlement is smaller, and the lateral displacement of the ground surface is larger when using the elastoplastic model in the plane strain condition. Additionally, the lateral displacement can be larger when the input parameters of the soil material were adjusted for the settlement to agree with the measured value. Hence, when predicting settlement and lateral displacement, it is important to consider the influence of the appropriate 3D effects.

Additionally, the detailed characteristics of the 3D effects of displacement are as follows:

\subsection{Settlement (Ground Surface)}

Figs. 7 and 8 show the settlement of the ground surface under the embankment in the final step. The vertical axis shows the settlement, and the horizontal axis shows the distance from the center of the embankment. According to the elastoplastic constitutive model, the settlement increases just below the top of the slope. This behavior is affected by the lateral flow below the slope. Furthermore, as $\mathrm{L} / \mathrm{B}$ decreases, the top of the slope approaches the central part of the embankment. Consequently, the settlement at the center and the $3 \mathrm{D}$ effect factor increase. Furthermore, the lateral flow is not observed when using the linear elastic model. As a result, the settlement matches that in the plane strain condition, and the 3D effect factor is not affected by L/B, as observed in Fig. 6(a).

\subsection{Lateral Displacement of Ground Surface}

Fig. 9 shows the distribution of lateral displacement of the ground surface in the final step. The vertical axis shows the lateral displacement and the horizontal axis shows the distance from the center of the embankment. As L/B decreases, the lateral displacement decreases and deviates from that in the plane strain condition. Accordingly, the $3 \mathrm{D}$ effect factor of the lateral displacement of the ground surface decreases with L/B. However, there is a difference in the trend of reduction between the elastoplastic model and the linear elastic model, as shown in Fig. 6(b). 


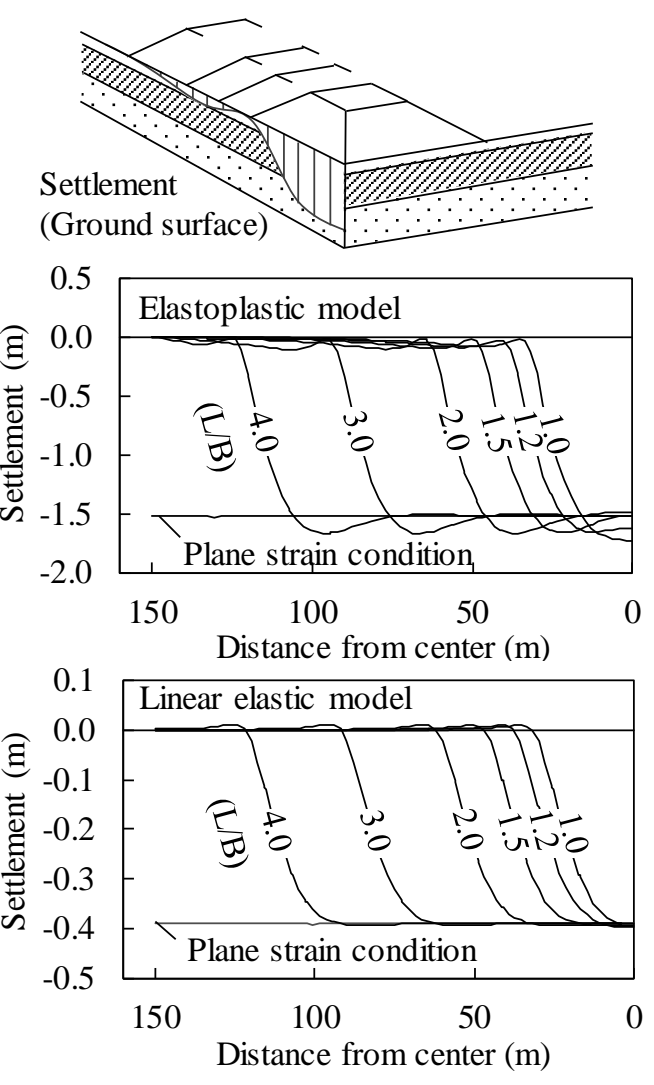

Fig. 7 Settlement of ground surface in the longitudinal direction (final step)

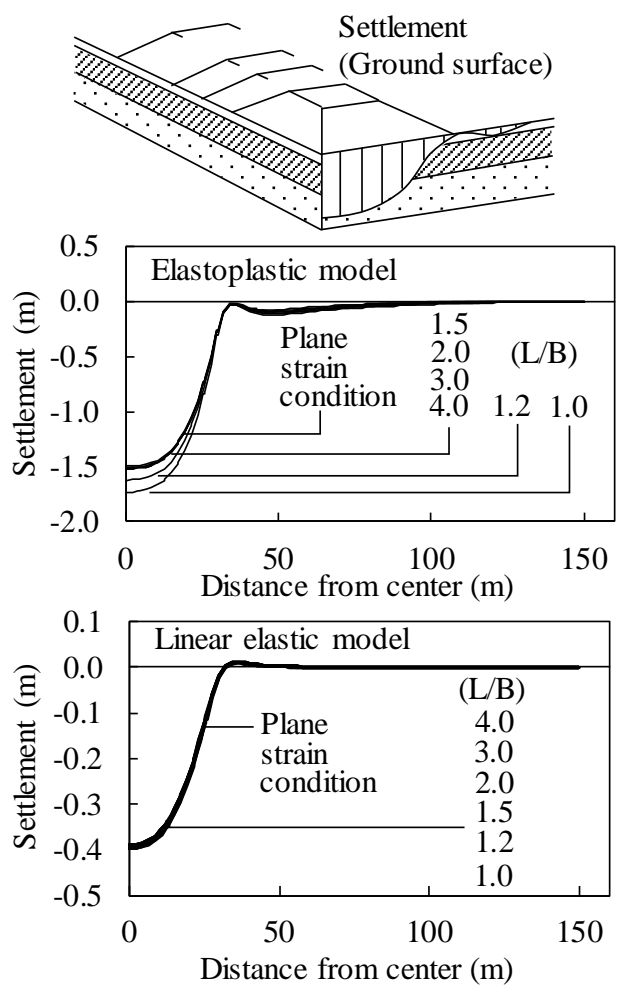

Fig. 8 Settlement of ground surface in the lateral direction (final step)
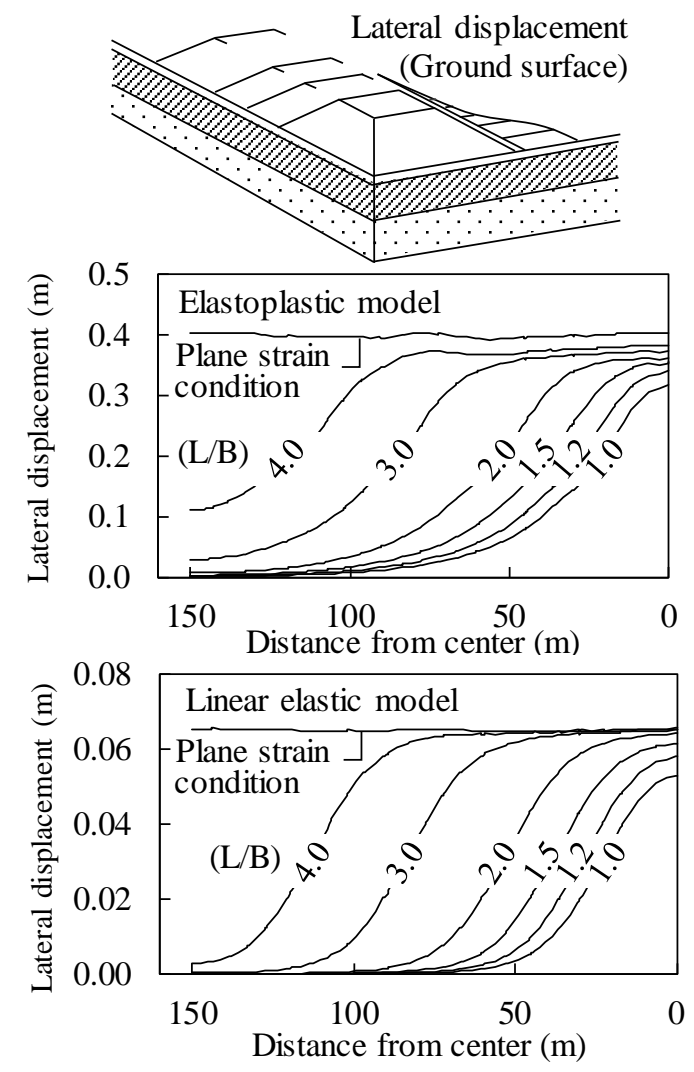

Fig. 9 Lateral displacement of ground surface (final step)

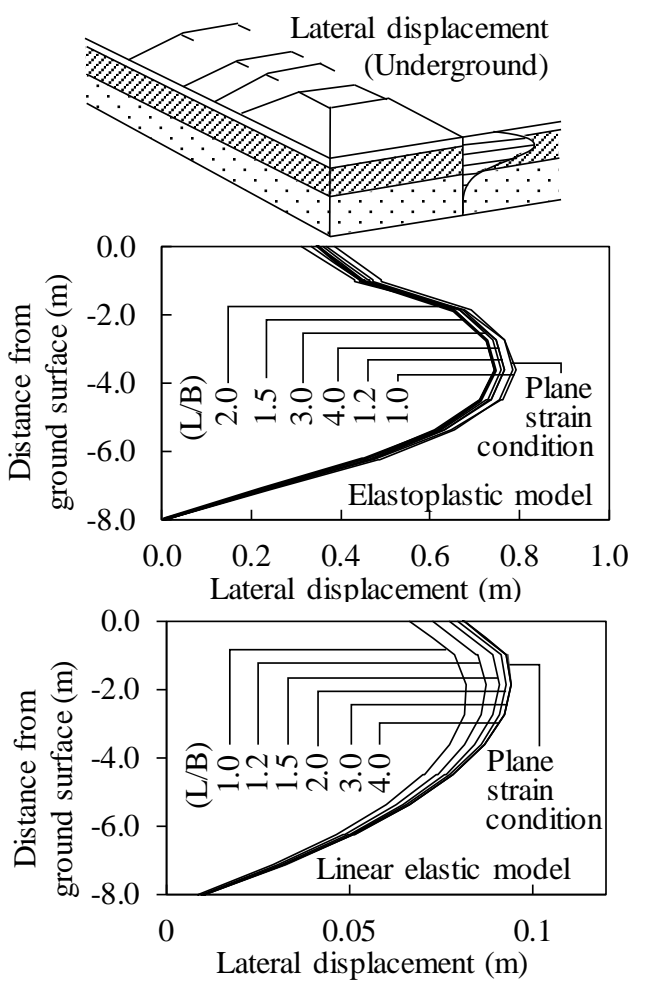

Fig. 10 underground lateral displacement (final step) 


\subsection{Underground Lateral Displacement}

Fig. 10 shows the distribution of lateral displacement (underground) below the toe of the slope in the final step. The vertical axis shows the distance from the ground surface and the horizontal axis shows the lateral displacement. There is a difference in deformation mode between the elastoplastic model and the linear elastic model. When using the elastoplastic model, a large displacement occurs because of the lateral flow. Additionally, in the linear elastic model, the 3D effect factor decreases as L/B decreases. However, in the elastoplastic model, it decreases temporarily and increases again as $\mathrm{L} / \mathrm{B}$ decreases, as shown in Fig. 6(c).

\section{MATERIAL PARAMETERS AND 3D EFFECT FACTORS}

As mentioned earlier, the 3D effects of the loading problem are affected by the soil material model. The input parameters of the soil material models have a significant effect on the predicted value of displacement. Therefore, to confirm the influence of these input values on the 3D effects, parametric analysis was performed by changing three parameters $(\mathrm{D}, \Lambda$, and $\mathrm{M})$ that control the behavior of the Sekiguchi-Ohta model.

In this study, the ranges of the changing parameters were quantitatively defined using the relationships between the estimation equation of parameters and previous soil test results. These relationships for the Sekiguchi-Ohta model were provided by lizuka et al. [21]. As shown in Fig. 11, the relationship between the plasticity index and the soil test results of each parameter is uniformly distributed around the dotted line indicated by the estimation equations. Therefore, as shown in Fig. 12 , a probability density function is defined, assuming that the deviation between each plot of the soil test result and that of the estimation equation is normally distributed. Consequently, the ranges of the changing parameters can be defined using the inclusion level of previous soil test results. The relationship between the dilatancy coefficient $\mathrm{D}$ and the plasticity index is not shown in previous studies [21]. However, the range of $\mathrm{D}$ can be defined from the data of compression index $\lambda$ by utilizing the estimation equations by Ohta, as shown in Fig. 4.

Table 4 lists the combinations of 12 parameter sets obtained using this method. To confirm the influence of the wider range of parameters, initial parameter settings were calculated using the flowchart shown in Fig. 4 and two plasticity indices (20\% and $60 \%$ ).
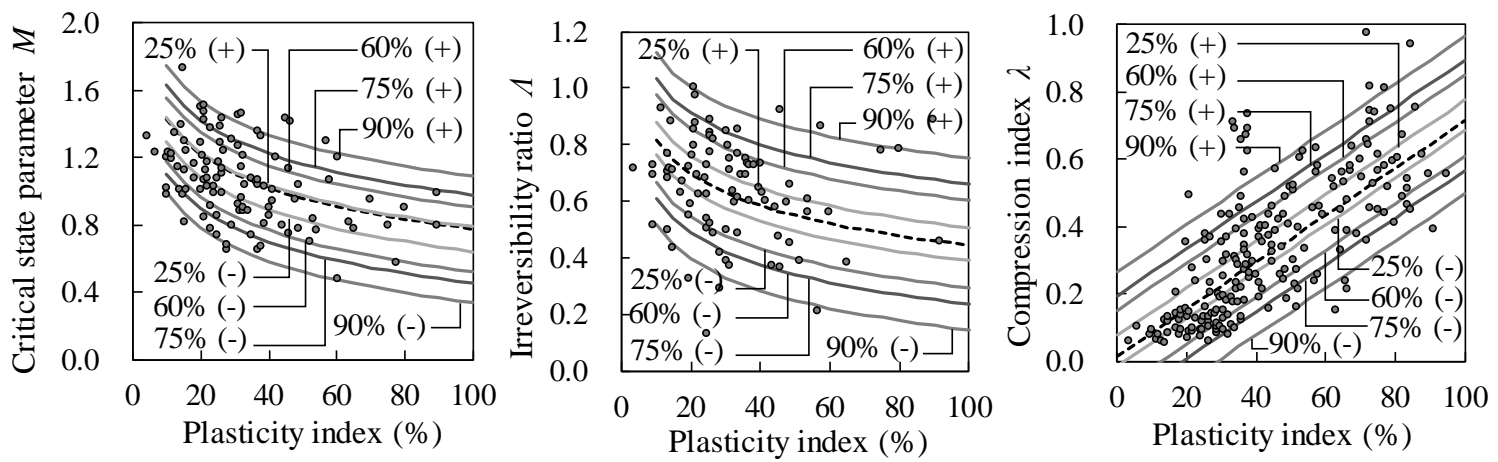

Fig 11. Relationship between plasticity index and soil test results of each parameter
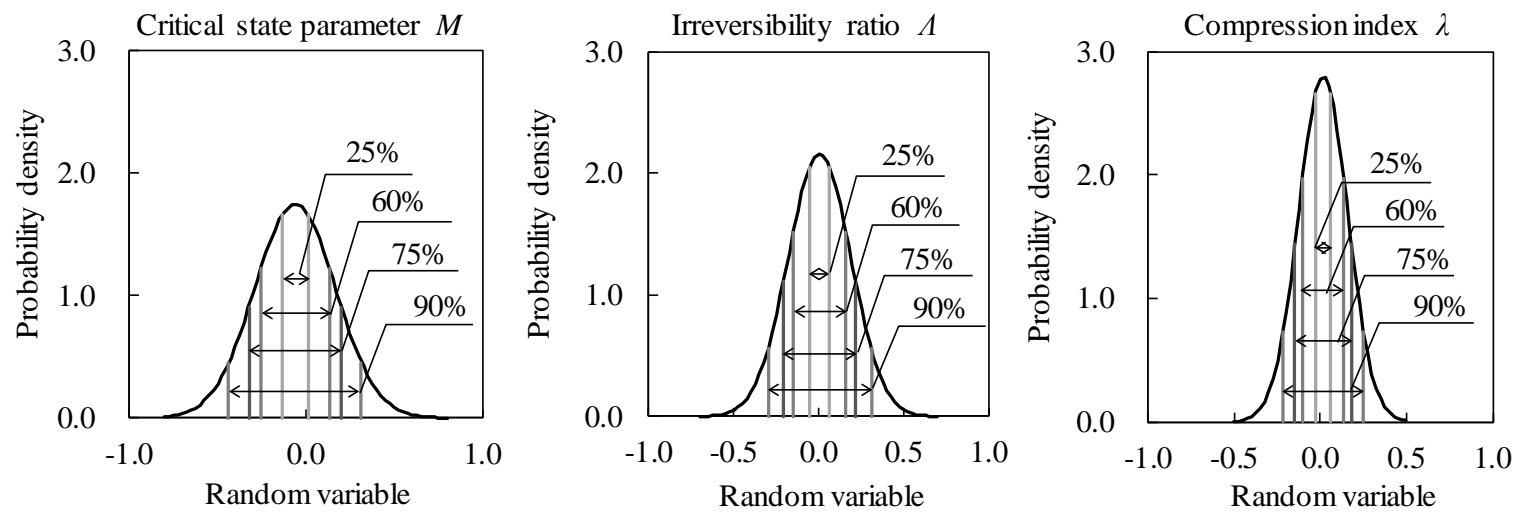

Fig 12. Probability density function and change region of each parameter 
Besides, a range of $25 \%$ was assumed for independent changing parameters. Furthermore, two models with $\mathrm{L} / \mathrm{B}$ values of 2.0 and 1.0 were used for this parametric analysis.

Table 4 Combinations of input parameters

\begin{tabular}{cccccc}
\hline PI & \multicolumn{2}{c}{ CASE } & $D$ & $\Lambda$ & $M$ \\
\hline 20 & \multicolumn{2}{c}{ Initial setting } & 0.051 & 0.697 & 1.220 \\
\cline { 2 - 6 }$\%$ & 1 & $D \uparrow$ & 0.068 & 0.697 & 1.220 \\
& 2 & $D \downarrow$ & 0.046 & 0697 & 1.220 \\
& 3 & $\Lambda \uparrow$ & 0.051 & 0.760 & 1.220 \\
& 4 & $\Lambda \downarrow$ & 0.051 & 0.642 & 1.220 \\
& 5 & $M \uparrow$ & 0.051 & 0.697 & 1.232 \\
& 6 & $M \downarrow$ & 0.051 & 0.697 & 1.086 \\
\hline 60 & \multicolumn{1}{c}{ Initial setting } & 0.089 & 0.524 & 0.912 \\
\hline$\%$ & 7 & $D \uparrow$ & 0.103 & 0.521 & 0.912 \\
& 8 & $D \downarrow$ & 0.090 & 0.521 & 0.912 \\
& 9 & $\Lambda \uparrow$ & 0.089 & 0.584 & 0.912 \\
& 10 & $\Lambda \downarrow$ & 0.089 & 0.466 & 0.912 \\
& 11 & $M \uparrow$ & 0.089 & 0.521 & 0.923 \\
& 12 & $M \downarrow$ & 0.089 & 0.521 & 0.778 \\
\hline
\end{tabular}

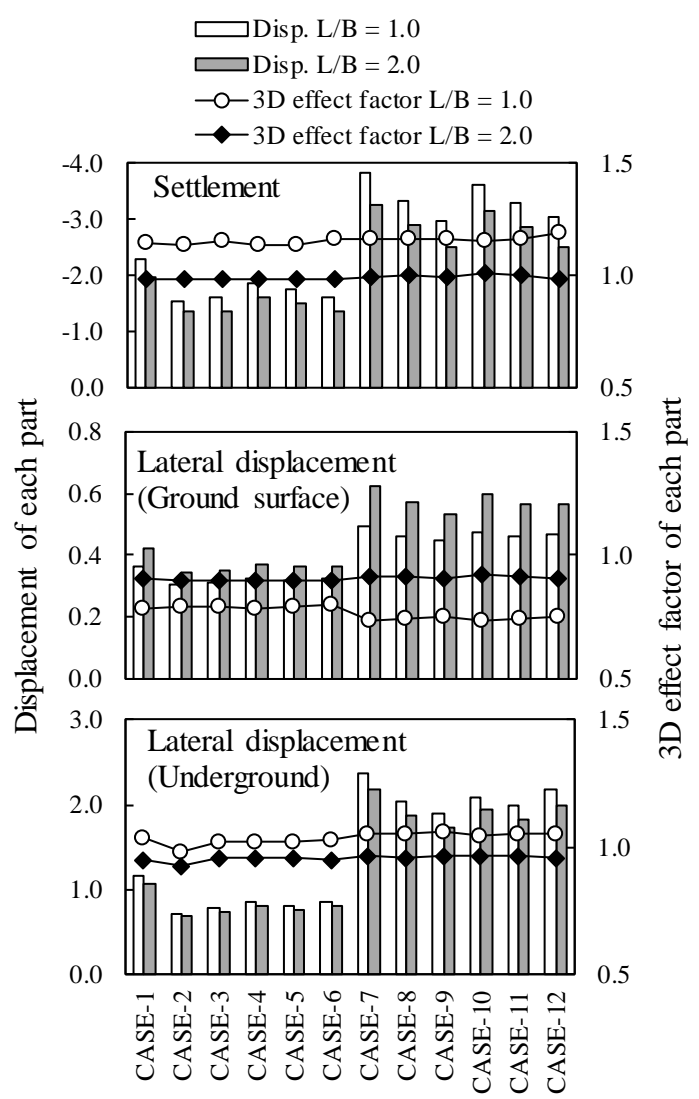

Fig. 13 Influence of material parameters on the 3D effect factor

The results of the parametric analysis for the 12 cases are shown in Fig. 13. The 3D effect factors are negligibly affected by the changes in the material parameters for both models ( $\mathrm{L} / \mathrm{B}=1.0$ and 2.0). Thus, for simple loading problems, the surrounding ground displacements can be estimated considering the 3D effects through the plane strain condition and utilizing the pre-calculated 3D effect factor at each focus point.

\section{CONCLUSION}

The main findings of this study can be summarized as follows:

(1) The 3D effects become prominent as $\mathrm{L} / \mathrm{B}$ decreases. It was confirmed that overvaluation and underestimation of displacement occur by applying the plane strain condition to the loading problem of short length embankment. The difference in the displacement of each part between plane strain condition and 3D analysis should be adjusted each with a different 3D effect factor.

(2) The shape of an embankment and the soil material model influence the 3D effect factors. However, the changes in the material parameters of the elastoplastic model do not significantly affect the 3D effect factors. Using this finding and the 3D effect factor, engineers can predict displacements (taking into account the 3D effects from the results of plane strain condition). This is can be useful for engineers to determine the input parameters for back analysis or probabilistic methods.

(3) Since this research is a basic study on the method of considering the 3D effects under the plane strain condition, a series of numerical experiments were performed under an imaginary condition. In this study, the lateral flow was shown to affect the 3D effects of displacement around the embankment when using the elastoplastic model for the clay layer. As the lateral flow is affected by the crosssectional shape of the embankment, thickness of the soft-soil layer, and dilatancy of the soils. Therefore, the range of application of the findings of this study should be confirm taking into account these conditions that affect the 3D effect factors.

\section{ACKNOWLEDGMENTS}

This study was supported by the study group of TERAKOYA. This study would not have been possible without their guidance. Besides, we would like to thank Editage (www.editage.com) for English language editing. 


\section{REFERENCES}

[1] Ohta H., Iizuka A., Omote Y. and Sugie S., 3-D analysis of soil/water coupling problems using elasto-viscoplastic constitutive relationships, Computer Methods and Advances in Geomechanics, Vol. 2, 1991, pp. 1191-1196.

[2] Ugai K., Leshchinsky D., Three-dimensional limit equilibrium and finite element analysis, Soils and Foundations, Vol. 35, No. 4, 1995, pp. 1-7.

[3] Roscoe K. H., Schofield A. and Thurairajah A., Yielding of clays in states wetter than critical, Geotechnique, Vol. 13, Issue 3, 1963, pp. 211240.

[4] Sekiguchi H., Ohta H., Induced anisotropy and time dependency in clays, Proc. Specialty Session 9. In 9th International Conference on Soil Mechanics and Foundation Engineering, 1977, pp. 229-237.

[5] Adachi T., Oka F., Constitutive equations for normally consolidated clay based on elastoviscoplasticity, Soils and Foundations, Vol. 22, No. 4, 1982, pp. 57-70.

[6] Hashiguchi K., Subloading surface model in unconventional plasticity, International Journal of Solids and Structures, Vol. 25, No. 8, 1989, pp. 917-945.

[7] Whittle A. J., Kavvadas M. J., Formulation of MIT-E3 constitutive model for overconsolidated clays, Journal of Geotechnical Engineering, Vol. 120, Issue 1, 1994, pp. 173198.

[8] Vermeer P. A., Neher H. P., A soft model that accounts for creep, Beyond 2000 in Computational Geotechnics-10 Years of Plaxis International. Balkema, Rotterdam, 1999.

[9] Asaoka A., Nakano M. and Noda T., Superloading yield surface concept for highly structured soil behavior, Soils and Foundations, Vol. 40, Issue 2, 2000, pp. 99-110.

[10] Ohno S., Iizuka A. and Ohta H., Two categories of new constitutive model derived from non-linear description of soil contractancy, Journal of Applied Mechanics, Vol. 9, 2006, pp. 407-414.

[11] Nakai T., Modeling of soil behavior based on tij concept, In Proceedings of the 13th Asian Regional Conference on Soil Mechanics and Geotechnical Engineering, Keynote Paper, Kolkata, 2007, pp. 69-89.

[12] Hirata M., Iizuka A. and Ohta H., Extension of the elasto-viscoplastic model in consideration of the pc-effect by secondary consolidation, Journal of JSCE, Ser. C (Geosphere Engineering), Vol. 69, No. 4, 2013, pp. 404416.

[13] Bergado D. T., Teerawattanasuk C., 2D and 3D numerical simulations of reinforced embankments on soft ground, Geotextiles and Geomembranes, Vol. 26, Issue 1, 2008, pp. 3955.

[14] Tanchaisawat T., Bergado D. T., Voottipruex P., 2D and 3D simulation of geogrid-reinforced geocomposite material embankment on soft Bangkok clay, Geosynthetics International, Vol. 16, Issue 6, 2009, pp. 420-432.

[15] Chaiyaput S., Bergado D. T. and Artidteang S., Measured and simulated results of a Kenaf Limited Life Geosynthetics (LLGs) reinforced test embankment on soft clay, Geotextiles and Geomembranes, Vol. 42, Issue 1, 2014, pp. 3947.

[16] Chai J. C., Shrestha S., Hino T., Ding W. Q., Kamo Y. and Carter J., 2D and 3D analyses of an embankment on clay improved by soilcement columns, Computers and Geotechnics, Vol. 68, 2015, pp. 28-37.

[17] Tschuchnigg F., Schweiger H. F., Embankment prediction and back analysis by means of 2D and 3D finite element analyses, Computers and Geotechnics, Vol. 93, 2018, pp. 104-114.

[18] Rujikiatkamjorn C., Indraratna B. and Chu J., 2D and 3D numerical modeling of combined surcharge and vacuum preloading with vertical drains, International Journal of Geomechanics, Vol. 8, Issue 2, 2008, pp. 144-156.

[19] Jean Lucas dos Passos Belo, Jefferson Lins da Silva, Reliability Analysis of a Controlled Stage-Constructed and Reinforced Embankment on Soft Ground Using 2D and 3D Models, Frontiers in Built Environment, 15, 2020.

[20] Ali S., Ramli B. N. and Nurly G., 3D Numerical Analysis of Centrifuge Tests on Embankments on Soft and Stiff Ground, Advanced Materials Research, 831, 2014, pp. 314-320.

[21] Iizuka A., Ohta H., A determination procedure of input parameters in elasto-viscoplastic finite element analysis, Soils and Foundations, Vol. 27, No. 3, 1987, pp. 71-87.

Copyright (C Int. J. of GEOMATE. All rights reserved, including the making of copies unless permission is obtained from the copyright proprietors. 